\title{
Nanomedicine Current Trends in Diabetes Management
}

\section{Shaik Rahiman ${ }^{1 *}$ and Bilal Ahmad Tantry ${ }^{2}$}

${ }^{1}$ Department of Biochemistry, College of Medicine, Al Jouf University, Saudi Arabia

${ }^{2}$ Department of Microbiology, College of Medicine, Al Jouf University, Saudi Arabia

\begin{abstract}
Nanomedicine is defined as integration of nanotechnology in medicine for the better human health care. The burgeoning new field of nanomedicine opened up by rapid advances in health care, creates myriad new opportunities for advancing medical science and disease treatment in human health care. Worldwide around 230 million people have been affected by Diabetes, is a chronic metabolic disorder due to the relative deficiency of insulin secretion and varying degrees of insulin resistance and is characterized by high circulating glucose. The major problems with conventional problems in glucose self monitoring are overcome by advances in nanomedicine, like Glucose nanosensors, layer-bylayer (LBL) technique, Carbon Nanotubes and Quantum Dots(QD's) etc. The major problem concerning about diabetes control with improper insulin administration routes also achieved by nanomedicine with better insulin delivery technology like oral insulin formulations, artificial pancreas, microsphere and nanopumps etc. Oxidative stress is a imperative for its morbidity towards diabetic complications like delayed wound healing is a well known problem in diabetes and it can be treated by use of some nanoparticles $\left(\mathrm{Al}_{2} \mathrm{O}_{3}, \mathrm{CeO}_{2}, \mathrm{Y}_{2} \mathrm{O}_{3}, \mathrm{AuNPs}\right)$ which act as a ROS scavenger. In this review, the chief scientific and technical aspects of nanomedicine related to diabetes and some pros and cons of nanotechnology based nanomedicine are discussed.
\end{abstract}

Keywords: Nanotechnology; Nanomedicine; Diabetes; Oral insulin; Nanoparticles

\section{Introduction}

Diabetes mellitus often referred to simply as diabetes, a lifelong progressive disease is a chronic metabolic disorder due to the relative deficiency of insulin secretion and varying degrees of insulin resistance and is characterized by high circulating glucose [1]. Currently it has reached epidemic proportion among the challenging unresolved health problems of the 21 st century. Worldwide around 230 million people have been affected by diabetes and the number are expected to reach around 366 million by 2030 [2]. Imbalance in body normal oxidative metabolism due to excessive levels of either molecular oxygen or Reactive Oxygen Species (ROS) leads to high glucose levels in blood (hyperglycemia) [3] results in metabolic disturbances (oxidative stress) and chronic complications in diabetes [4]. The management of diabetic conditions by insulin therapy has several drawbacks like insulin resistance and in chronic treatment causes anaeroxia nervosa, brain atrophy and fatty liver. Currently several research studies are going on with the aid of nano size particles to overcome such limitations in diabetes management.

Nanotechnology can be defined as the science and engineering involved in the design, synthesis, characterization and application of materials and devices whose smallest functional organization in at least one dimension is on the nanometer scale (one-billionth of a meter) $[5,6]$. When this science is applied specifically to the problems of medicine, it is called 'Nanomedicine' [7,8]. The nanomedicine scale limitations excludes at the lower end atoms $(0.1 \mathrm{~nm})$ and at the upper end biological entities such as bacteria $(1000-10000 \mathrm{~nm})$ and body cells (eg. White blood cell $10000 \mathrm{~nm}$ ).Human body has configured many of its biocomponents as nanostructures, including proteins, mitochondria, ion channels, membranes, secretory granules, lysosomes and so on, but many new nanomaterials and structures are now being manufactured that might be of use in medicine, such as nanoparticles, capsules, films and tubes, and complex molecules( e.g fullerenes) [9]. Nanomedicine can be classified into (a) measurement (or 'nanometrology'), which concerns either measuring very small amounts of analytes (e.g. microphysiometer) or using very small- sized devices for measuring (e.g. Quantum dots). (b) Therapy, as all of the manipulations and constructions of materials at the nano-level ultimately concern therapies (e.g. Artificial nanopancreas) [10].

\section{Nanomedicine application in glucose monitoring}

The major problems with conventional finger-prick capillary blood glucose self monitoring are widely accepted [7]. It is painful (leading to non-compliance) and cannot be performed when the patient is sleeping or driving a motor vehicle (times when the patient is especially vulnerable to hypoglycaemia) and, because it is intermittent, it can miss dangerous fluctuations in blood glucose concentrations between tests. Currently in market several implanted needle-type enzyme electrodes or microdialysis probes are available for continuous glucose monitoring but those are limited impaired responses and unpredictable signal drift in vivo, and also need calibration against capillary glucose tests and contributes to sensor inaccuracies [11-13]. The repeated insertion of the sensor probe is also semi-invasive. This conventional problem got solution by the application of nanotechnology in medicine (Table 1).

\section{Glucose nanosensors}

Improved nanotechnique for in vivo glucose monitoring is a 'smart tattoo' composed of glucose-responsive, fluorescence-based nanosensors implanted into the skin but interrogated from outside the body, thus gives non-invasive measurements. In this method sensors that use fluorescence for detecting analyte changes have some advantages compared to the more usual implanted electrochemical electrodes, as they should not be susceptible to electroactive tissue

*Corresponding author: Dr. Shaik Rahiman, College of Medicine, Al Jouf University, Sakaka, Al Jouf, Saudi Arabia, PO.Box 2014, Postal code: 75471, Tel: +966500451731; E-mail: rahimhi@gmail.com

Received April 09, 2012; Accepted May 19, 2012; Published May 23, 2012

Citation: Rahiman S, Tantry BA (2012) Nanomedicine Current Trends in Diabetes Management. J Nanomed Nanotechol 3:137. doi:10.4172/2157-7439.1000137

Copyright: (c) 2012 Rahiman S, et al. This is an open-access article distributed under the terms of the Creative Commons Attribution License, which permits unrestricted use, distribution, and reproduction in any medium, provided the original author and source are credited. 
interfearence that contribute to the instability of present sensors, and because Near infrared (NIR) light with a wavelength above about 600 $\mathrm{nm}$ passes through several centimeters of tissue, allowing implantation and non-invasive measurement at the body surface.

Currently a number of biological or artificial receptors for glucose have been described, which can transduce glucose concentrations into changes in fluorescence, including lectins (plant lectin concanavalin-A) [14,15], enzymes (hexokinase) [16], bacterial binding proteins(l Glucose/Galactose-Binding Protein (GBP) [17-20] and boronic acid derivatives [21], and which might be engineered as nanosensors.

\section{The layer-by-layer (LBL) technique}

Glucose sensors are encapsulated in a form that can be implanted in the body and yet maintain functionality i.e, avoiding degradation, denaturation, leakage and foreign body reactions, while retaining glucose access and detectable signal change. An example of a technology that may be appropriate for this is electrostatic layer-by-layer (LBL) nanoassembly of capsules composed of alternating layers of positively and negatively charged polymers, thereby building up a very thinfilm with tunable permeability and controlled biocompatibility [22-28]. A typical thickness is approximately $10 \mathrm{~nm}$ for six bilayers. An early use of such nanofilms has been in the construction of microvesicles for glucose sensing [23-27]. These might eventually be implanted in the dermis or subcutaneous tissue as a 'smart tattoo', with the semipermeable capsules allowing entry of glucose from the interstitial fluid but containing and protecting the sensor materials $[25,28]$. If the sensing mechanism involves a near infrared (NIR)-based fluorescence assay, the glucose sensors can be excited and the fluorescence emission interrogated from outside the body, since NIR light passes through several centimeters of tissue. Therefore, this might be the basis for a noninvasive glucose-sensing technology. Among the strategies for making microvesicles by the LBL technique are sequential absorption of polyelectrolytes around crystals of a glucose-sensing enzyme such as glucose oxidase [23], or absorption of a glucose-recognition molecule such as glucose oxidase, apo-glucose oxidase (the enzyme without the prosthetic group), concanavalin A or a glucose-binding protein (GBP) onto a artificial template (e.g.,Calcium carbonate), followed by stepwise addition of the charged polypeptides (e.g., polyl-lysine and polyl-glutamic acid). The template is then dissolved with ethylenediaminetetraacetic acid (EDTA), leaving a hollow microcapsule containing the sensor.

\section{Carbon nanotubes}

Carbon nanotubes discovered in 1991 [29] are tubular structures like a sheet of graphite rolled into a cylinder capped at one or both ends by a buckyball. Nanotubes can be Single Walled Carbon Nanotube (SWCNT) or Multiwalled Carbon Nanotube (MWCNT) in concentric fashion. The microphysiometer is built from multiwalled carbon nanotubes, which are like several flat sheets of carbon atoms stacked and rolled into very small tubes. Which are like several flat sheets of carbon atoms stacked and rolled into very small tubes. The nanotubes are electrically conductive and the concentration of insulin in the chamber can be directly related to the current at the electrode and the nanotubes operate reliably at $\mathrm{pH}$ levels characteristic of living cells. Current detection methods measure insulin production at intervals by periodically collecting small samples and measuring their insulin levels. The new sensor detects insulin levels continuously by measuring the transfer of electrons produced when insulin molecules oxidize in the presence of glucose. When the cells produce more insulin molecules, the current in the sensor increases and vice versa, allowing monitoring insulin concentrations in real time [30].
Single-Walled Carbon Nanotubes (SWCNTs) fluorescence in the NIR spectral region and since they also suffer no photobleaching, SWCNTs are thus particularly suitable as fluorophore probes in glucose sensors designed for eventual in vivo use [31]. SWCNTs have been employed in a fluorescence-based competitive glucose sensing strategy where dextran is bound to the carbon nanotubes, and binding of concanavalin A or apo-glucose oxidase to the dextran-SWCNT attenuates the fluorescence, which is reversed by the addition of glucose [31]. Apo-glucose oxidase has also been covalently attached to polyvinyl alcohol to make a glucose responsive hydrogel that can be monitored by the fluorescence of SWCNT embedded in the hydrogel [32].

\section{Quantum dots}

Quantum Dots (QDs) can be used for biomedical purposes as a diagnostic as well as therapeutic tool. These arenanosized $(2-10 \mathrm{~nm})$ semiconductor crystals, such as cadmium selenide, coated with a shell, such as zinc sulfide [33]. QDs have been used as a fluorescent probe in several biosensor applications, often using As Fluorescence-Resonance Energy Transfer (FRET), because they display high-intensity fluorescence that is excitable over a broad range of wavelengths, but have an emission wavelength that is dependent on the particle size. For example, based a glucose sensor on FRET between QDs as a fluorescence donor and gold nanoparticles as an acceptor the, glucose displaces concanavalin A-labeled QDs from gold-labeled cyclodextrin, thereby, reducing FRET and increasing fluorescence [34].

\section{Nanomedicine in management of diabetes}

Worldwide 285 million peoples are suffering with a pervasive, chronic and often insidious diabetes is caused by inability of the pancreas to control the blood glucose concentration [35]. The preferred approach of insulin intake since the past decades is via subcutaneous route, which, nonetheless, often fails to mimic the glucose homeostasis observed in normal subjects [36] because in this approach insulin delivered to the peripheral circulation rather than to the portal circulation and directly into the liver, which is the physiological route in normal individuals [37]. Furthermore, multiple daily injections of insulin referred for poor patient compliance are associated with subcutaneous route treatment. Therefore, many studies were done to find out the better and safer route of insulin administration, in this regards application of nanotechnology in medicine revealed a solution to overcome this problem.

\section{Oral insulin}

In diabetic patients oral administration of insulin can be beneficial not only to alleviate the pain and trauma caused by injections, but it can mimic the physiological fate of insulin as well [36,38]. However, oral administration of protein drugs, such as insulin, encounters difficulties with low $\mathrm{pH}$ of gastric medium in the stomach and its digestive enzymes as well as intestinal epithelium is a major barrier to the absorption of molecular weight hydrophilic macromolecules (e.g proteins, polysaccharides and nucleic acids) before it reach the target cell for it specific action [39]. Therefore, attentions have been given to improving the paracellular delivery of hydrophilic macromolecules with the application of nanotechnology in diabetic research [40]. The nanomedicine technologies that may be employed for oral insulin delivery include prodrugs (insulin-polymer conjugation), micelles, liposomes, solid lipid nanoparticles (NPs) and NPs of biodegradable polymers.

The prodrug technology that is used most often for drug 
formulation is PEGylation (i.e., drug conjugation to Polyethylene Glycol [PEG]) for enhanced solubility, permeability and stability. Insulin-PEG prodrugs have shown great advantages in oral delivery [41]. ScottMoncrieff et al. [42] developed a system of bilesalt and fattyacid mixed micelles and found that those micelles containing $30 \mathrm{mM}$ sodium glycocholate and $40 \mathrm{mM}$ linoleic acid significantly improved enteral insulin absorption. Unfortunately, micelles did not seem to be ideal for delivery of hydrophilic drugs. Instead, liposomes can have much better performance for oral insulin delivery. This liposomal delivery system containing glycocholate as an enzyme inhibitor and permeat ion enhancer has been developed recently for oral insulin delivery, which showed better protect ion of insulin against enzymatic degradation by pepsin, trypsin and achymotrypsin [43]. NPs of US FDAapproved biodegradable polymers, such as poly (lacticcoglycolic acid) (PLGA) and polycaprolactone, were also investigated for oral insulin delivery. However, those NPs may not be ideal for delivery of hydrophilic drugs. Nevertheless, how it can be applied to oral delivery for hydrophilic drugs such as insulin is still a challenge.

Therefore, attention has been given to improving the paracellular transport of hydrophilic drugs $[44,45]$. A variety of intestinal permeation enhancers including chitosan (CS) have been used for the assistance of the absorption of hydrophilic macromolecules [46]. Therefore, a carrier system is needed to protect protein drugs from the harsh environment in the stomach and small intestine, if given orally [47]. Additionally, CS nanoparticles (NPs) enhanced the intestinal absorption of protein molecules to a greater extent than aqueous solutions of CS in vivo [48]. The insulin loaded NPs coated with muco adhesive CS may prolong their residence in the small intestine, infiltrate into the mucus layer and subsequently mediate transiently opening the tight junctions between epithelial cells while becoming unstable and broken apart due to their $\mathrm{pH}$ sensitivity and/or degradability. The insulin released from the broken-apart NPs could then permeate through the paracellular pathway to the bloodstream, its ultimate destination.

\section{Microsphere for oral insulin production}

The most promising strategy to achieve oral insulin is the use of a microsphere system which is inherently a combination strategy. Microspheres act both as protease inhibitors by protecting the encapsulated insulin from enzymatic degradation within its matrix and as permeation enhancers by effectively crossing the epithelial layer after oral administration [37].

\section{Artificial pancreas}

Development of artificial pancreas could be the permanent solution for diabetic patients. The original idea was first described in 1974. The concept of its work is simple: a sensor electrode repeatedly measures the level of blood glucose; this information feeds into a small computer that energizes an infusion pump, and the needed units of insulin enter the bloodstream from a small reservoir [49].

Another way to restore body glucose is the use of a tiny silicon box that contains pancreatic beta cells taken from animals. The box is surrounded by a material with a very specific nanopore size (about 20 nanometers in diameter). These pores are big enough to allow for glucose and insulin to pass through them, but small enough to impede the passage of much larger immune system molecules. These boxes can be implanted under the skin of diabetes patients. This could temporarily restore the body's delicate glucose control feedback loop without the need of powerful immunosuppressant that can leave the patient at a serious risk of infection [50]. Scientists are also trying to create a nanorobot which would have insulin departed in inner chambers, and glucose level sensors on the surface. When blood glucose levels increase, the sensors on the surface would record it and insulin would be released. Yet, this kind of nano-artificial pancreas is still only a theory [51].

\section{Nanopumps}

The nanopump is a powerful device and has many possible applications in the medical field. The first application of the pump, introduced by Debiotech for insulin delivery. The pump injects insulin to the patient's body in a constant rate, balancing the amount of sugars in his or her blood. The pump can also administer small drug doses over a long period of time [52].

\section{Nanoparticles anti oxidative role in diabetes}

Oxidative stress plays a foremost role in etiology of several diabetic complications [53-55]. Major problem with diabetes patients is delayed healing of wound and still challenging its complete cure. It is a complex programmed sequence of cellular and molecular processes [56]. Healing impairment is characterized by delayed cellular infiltration and granulation tissue formation, reduced angiogenesis, decreased collagen, and its organization $[57,58]$. The mechanism of this alteration is thought to result from production of high level of ROS production that leads to premature apoptosis of inflammatory cells, which in turn impairs keratinocyte endothelial cells, fibroblasts, and collagen metabolism [59]. Some of the nanoparticle now a day are preparing in a manner that act as free radical scavenger [60].

Cerium oxide $\left(\mathrm{CeO}_{2}\right)$ plays major active role due to its excellent free radical scavenging potentials [62]. This metal oxide is monodisperse particle with single crystal and few twin boundaries [61] with expanded lattice parameter [63]. Cerium atom characterized by both +4 and +3 oxidation states. This dual oxidation state means that these nanoparticles have oxygen vacancies [64]. The loss of oxygen and the reduction of $\mathrm{Ce}^{+}$to $\mathrm{Ce}^{+}$is accompanied by creation of an oxygen vacancy. This property enhance $\mathrm{CeO}_{2}$ nanoparticle attractive for wound healing process followed by scavenging properties.

Yttrium oxide $\left(\mathrm{Y}_{2} \mathrm{O}_{3}\right)$ is now a day considered most significant due to its highest free energy of oxide formation from elemental yttrium among known metal oxides [65]. It is characterized by only small changes from stoichiometry under normal conditions of temperature and pressure [66] and by atmospheric absorption of $\mathrm{H}_{2} \mathrm{O}$ and $\mathrm{CO}_{2}$ [67] These groups of nanoparticles are relatively non toxic to neutrophiles and macrophages, where $\mathrm{CeO}_{2}$ and $\mathrm{Y}_{2} \mathrm{O}_{3}$ particles protect cells from death due to oxidative stress. Cerium and yttrium oxide nanoparticles are able to rescue cells from oxidative stress-induced cell death in a manner that appears to be dependent upon the structure of the particle but independent of its size within the range of 6-1000 $\mathrm{nm}$. This might be useful for the diabetic wound healing.

Literature shows three alternative explanations for the cerium oxide and yttrium oxide particles protection against oxidative stress. (a) They may act as direct antioxidants, block ROS production, which inhibit programmed cell death pathway (b) They may directly cause a low level of ROS production, which rapidly induces a ROS defense system before the glutamate-induced cell death program is complete and (c) The latter is a form of preconditioning that could be caused by the exposure of cells to particulate material known to induce low levels of ROS [68].

Nanoparticles made of other metal oxides were also considered for its potential scavenger behavior. These included particles aluminum 
oxide $\left(\mathrm{Al}_{2} \mathrm{O}_{3}\right)$, commonly known as alumina [69] and Silver nitrate. Silver nitrate has been used in the clinical setting as an antimicrobial agent for the treatment of treatment of chronic wounds [70]. It is effective against a broad range of aerobic, anaerobic, Gram-negative and Gram-positive bacteria, yeast, filamentous fungi and viruses [7075]. It has been reported a novel $\mathrm{Ag}^{+}$loaded zirconium phosphate nanoparticle plays crucial role in diabetic wound healing [76].

The gold nanoparticles (AuNPs), are known for their tremendous applications in the field of theapeutics and diagonosis. AuNPs are emerging nanomedicine which is renowned for its promising therapeutic possibilities, due to its significant properties such as biocompatibility, high surface reactivity, resistance to oxidation and plasmon resonance [77]. The ability of gold nanoparticles in inhibiting the lipid from peroxidation thereby preventing the ROS generation has restored the imbalances in the antioxidants [78]. Selvaraj BarathManiKanth et al. [79] reported the anti-oxidative and antihyperglycemic activities of gold nanopartcles, whereas the mechanism of the delayed wound healing in diabetes is still unclear.

\section{Applications of nanotechnology in health care and disease}

Nanotechnology, by development of engineered nanomaterials, is a rapidly growing industry with great potential and applications in many areas, including nanomedicine. Nanomaterials (NMs) have unique properties and applications when it comes to drug delivery and imaging, and they have the potential to improve diagnostics and therapy of many human disorders, including neurodegenerative disorders, by their ability to cross the Blood Brain Barrier (BBB). The nanosize and the large surface area of nanoparticles (NPs) reflects increased reactivity, and even an inert bulk compound, such as gold, may elicit a response in humans when administered as a NMs. However, concern has been raised that the properties that make NMs unique and so useful could also be coupled to unintentional effects on human health. Thus, it is important to obtain information about the potential toxicity of NMs to discover and prevent serious unwanted human effects. The goal must be to realize the great opportunities and benefits of NMs while at the same time minimizing the risk related to their applications.

Nanomedicine is a field with continuous progress, introducing novel applications in many health care areas. The underlying motivation is improvement of quality of life with economic and social benefits. Some of the most promising areas are the following $[80,81]$.

- Nanodiagnostics (molecular diagnostics, imaging using NPbased contrast materials, nanobiosensors)

- Nanopharmaceuticals (targeted drug delivery, nanotechnologybased drugs, implanted nanopumps, nanocoated stents)

- Reconstructive surgery (tissue engineering, implantation of rejection resistant artificial tissues and organs)

- Nanorobotics (vascular surgery, detection and destruction of cancer)

- Nanosurgery (nanolasers, nanosensors implanted in catheters)

- Regenerative medicine (tissue repair)

- Ultrafast DNA sequencing.

\section{Potential toxicity of Nanoparticles}

There is as yet no reason to think that nanomaterials pose a certain toxic threat or that any possible harmful effects cannot be assessed and managed as is done for any new pharmaceuticals, diagnostics or medical materials. However, as there is a lack of information and research on nanomaterial toxicity, it is important to consider the potential health and safety issues. The determinants of particle toxicity are known to be the large surface area and chemical reactivity in relation to small size (and thus the ability to generate reactive oxygen species) and the ability to penetrate tissues and cells [82]. Thus, nanoparticles are likely to be more hazardous than the same chemicals in larger form, and free particles more toxic than fixed ones [83]. The potential cytotoxicity of QDs is an example to consider, because at high concentrations harmful effects on embryo development and cell viability and function have been recorded [84]. Nanoparticles such as QDs most likely need to be passivated with less toxic materials to improve biocompatibility, for example with silica [85]. Intratracheal instillation of carbon nanotube particles in mice has shown that carbon nanotubes have the potential to cause varied lung pathologies like epitheloid granuloma, interstitial inflammation, peribronchial inflammation and necrosis of lung. The toxicity produced by carbon nanotube was found to be greater than that produced by carbon black and quartz [86]. Studies done on monkeys and rats have shown accumulation of carbon and manganese nanoparticles in the olfactory bulb through the olfactory pathway $[87,88]$. This shows that nanoparticle mediated delivery can in future provide a means of alternate route, circumventing the blood brain barrier. However, this can also result in the inflammatory reactions in the brain which needs to be evaluated. Radomski et al [89] have observed the proaggregatory effects of nanotubes on platelets in vitro studies and acceleration of vascular thrombosis in rat. The nanoparticles can reach the circulation and reach different organs and systems and possibly results in toxicity [90]. These have been studied in vitro and in animal models and the effect on human system is difficult to extrapolate from such studies. Their use in humans require further research and much needed caution.

\section{Conclusion}

This article was an attempt to review the chief scientific and technical aspects of nanomedicine in related to diabetes. However the expectation form nanotechnology in medicine are high and the potential benefits are endlessly enlisted, the safety of nanomedicine is not yet clear. Nanomedicine shows great potential for the future diabetic management and at the moment the suggested benefits in diabetic health care outweigh the possible dangers of nanoparticles use in medicine. Here we conclude that use of nanomedicine in diabetic care is in initial stage, but progress is rapid. Diabetes has many remaining problems; nanomedicine is likely to be a key technology for solving many of them and will be a core technology in diabetic research.

\section{References}

1. Aylward GW (2005) Progressive changes in diabetics and their management Eye (Lond) 19: 1115-1118.

2. Wild S, Roglic G, Green A, Sicree R, King H (2004) Global prevalence of diabetes: estimates for the year 2000 and projections for 2030. Diabetes Care 27: 1047-1053.

3. Aronson D ( 2008) Hyperglycemia and pathobiology of diabetic complications Adv Cardiol 45: 1-16.

4. Harrison D, Griendling KK, Landmesser U, Hornig B, Drexler H (2003) Role of oxidative stress in atherosclerosis. Am J Cardiol 91: 7A-11A.

5. Emerich DF, Thanos CG (2003) Nanotechnology and medicine. Expert Opin Biol Ther 3: 655-663.

6. Sahoo SK, Labhasetwar V (2003) Nanotech approaches to drug delivery and imaging. Drug Discov Today 8: 1112-1120. 
Citation: Rahiman S, Tantry BA (2012) Nanomedicine Current Trends in Diabetes Management. J Nanomed Nanotechol 3:137. doi:10.4172/21577439.1000137

7. Moghimi SM, Hunter AC, Murray JC (2005) Nanomedicine: current status and future prospects. FASEB J 19: 311-330.

8. Freitas RA Jr (2005) What is nanomedicine? Nanomedicine 1: 2-9.

9. Kroto HW, Heath JR, O'Brien SC, Curl RF, Smalley RE (1985) C60: Buckminste fullerene. Nature 318: 162-163.

10. Pickup JC, Zhi ZL, Khan F, Saxl T, Birch DJ, (2008) Nanomedicine and its potential in diabetes research and practice. Diabetes Metab Res Rev 24: 604610.

11. Mastrototaro JJ (2000) The MiniMed continuous glucose monitoring system Diabetes Technol Ther 2: S13-S18.

12. Maran A, Crepaldi C, Tiengo A, Grassi G, Vitali E, et al. (2002) Continuous subcutaneous glucose monitoring in diabetic patients: A multicentre analysis. Diabetes Care 25: 347-352.

13. Garg S, Zisser H, Schwarz S, Bailey T, Kaplan R, et al. (2006) Improvement in glycemic excursions with a transcutaneous, real-time continuous glucose sensor : a randomized controlled trial. Diabetes Care 29: 44-50.

14. McCartney LJ, Pickup JC, Rolinski OJ, Birch DJ (2001) Near-infrared fluorescence lifetime assay for serum glucose based on allophycocyaninlabeled concanavalin A. Anal Biochem 292: 216-221.

15. Ballerstadt R, Schulz JS (2000) A fluorescence affinity hollow fiber sensor for continuous transdermal glucose monitoring. Anal Chem 72: 4185-4192.

16. Hussain F, Birch DJS, Pickup JC (2005) Glucose sensing based on the intrinsic fluorescence of sol-gel immobilized yeast hexokinase. Anal Biochem 339: 137143

17. Marvin JS, Hellinga HW (1998) Engineering biosensors by introducing fluorescence allosteric signal transduction: Construction of a novel glucose sensor. J Am Chem Soc 120: 7-11.

18. Tolosa L, Gryczynski I, Eichhorn LR, Dattelbaum JD, Castellano FN, et al. (1999) Glucose sensor for low-cost lifetime-based sensing using a genetically engineered protein. Anal Biochem 267: 114-120.

19. Salins LL, Ware RA, Ensor CM, Daunert S (2001) A novel reagentless sensing system for measuring glucose based on the galactose/glucose-binding protein. Anal Biochem 294: 19-26.

20. Ye K, Schultz JS (2003) Genetic engineering of an allosterically based glucose indicator protein for continuous glucose monitoring by fluorescence resonance energy transfer. Anal Chem 75: 3451-3459.

21. Pickup JC, Hussain F, Evans ND, Rolinski OJ, Birch DJ (2005) Fluorescencebased glucose sensors.Biosens Bioelectron 20: 2555-2565

22. Ariga K, Hill JP, Ji Q (2007) Layer-by-layer assembly as a versatile bottomup nanofabrication technique for exploratory research and realistic application. Phys Chem Chem Phys 9: 2319-2340.

23. Trau D, Rennenberg R (2003) Encapsulation of glucose oxidase microparticles within a nanoscale layer-by-layer film: immobilization and biosensor applications. Biosens Bioelectron 18: 1491-1499.

24. Chinnayelka S, McShane MJ (2006) Glucose sensors based on microcapsules containing an orange/red competitive binding resonance energy transfer assay. Diabetes Technol Ther 8: 269-278.

25. McShane M, Ritter D (2010) Microcapsules as optical biosensors. J Mater Chem 20: 8189-8193.

26. Zhi ZL, Haynie DT (2006) High-capacity functional protein encapsulation in nanoengineered polypeptide microcapsules. Chem Commun (Camb) 14: 147149.

27. Zhi ZL, Haynie DT (2006) Straightforward and effective protein encapsulation in polypeptide-based artificial cells. Artif Cells Blood Substit Immobil Biotechnol 34: 189-203.

28. Pickup JC, Zhi ZL, Khan F, Saxl T, Birch DJ (2008) Nanomedicine and its potential in diabetes research and practice. Diabetes Metab Res Rev 24: 604610.

29. lijima S (1991) Helical microtubules of graphitic carbon. Nature 354: 56-58.

30. http://nextbigfuture.com/2008/04/microphysiometer-using-multiwall-carbon. $\mathrm{html}$

31. Barone PW, Parker RS, Strano MS (2005) In vivo fluorescence detection of glucose using a single-walled carbon nanotube optical sensor: design, fluorphore properties, advantages, and disadvantages. Anal Chem 77: 75567562.

32. Barone PW, Yoon H, Ortiz-Garcia R, Zang J, Ahn JH, et al. (2009) Modulation of single-walled carbon nanotube photoluminescence by hydrogel swelling. ACS Nano 3: 3869-3877.

33. Michalet X, Pinaud FF, Bentolila LA, Tsav JM, Doose S, et al. (2005) Quantum dots for live cells, in vivo imaging, and diagnostics. Science 307: 538-544.

34. Tang B, Cao L, Xu K, Zhuo L, Ge J, et al. (2008) A new biosensor for glucose with high sensitivity and selectivity in serum based on fluorescence resonance energy transfer (FRET) between CdTe quantum dots and Au nanoparticles. Chemistry 14: 3637-3644.

35. Shaw JE, Sicree RA, Zimmet PZ (2010) Global estimates of the prevalence of diabetes for 2010 and 2030. Diabetes Res Clin Pract 87: 4-14

36. Carino GP, Mathiowitz E (1999) Oral insulin delivery. Adv Drug Del Rev 35 249-257.

37. Clore J, ThurbyHay L (2004) Basal insulin therapy. Curr Diab Rep 4: 342-345.

38. Arbit E, Kidron M (2009) Oral insulin: the rationale for this approach and current developments. J Diabetes Sci Technol 3: 562-567.

39. Binder C, Lauritzen T, Faber O, Pramming S (1984) Insulin pharmacokinetics. Diabetes Care 7: 188-199.

40. Feng SS (2008) Nanomedicine: nanoparticles of biodegradable polymers for cancer diagnosis and treatment. COSMOS 4: 185-201.

41. Calceti P, Salmaso S, Walker G, BernkopSchnürch A (2004) Development and in vivo evaluation of an oral insulinPEG delivery system. Eur J Pharm Sci 22 315-323.

42. ScottMoncrieff JC, Shao Z, Mitra AK (1994) Enhancement of intestinal insulin absorption by bile salt-fatty acid mixed micelles in dogs. J Pharm Sci 83: 14651469

43. Niu M, Lu Y, Hovgaard L, Wu W (2011) Liposomes containing glycocholate as potential oral insulin delivery systems: preparation, in vitro characterization, and improved protection against enzymatic degradation. Int $\mathrm{J}$ Nanomed 6 : 1155-1166

44. Kotz'e AF, Lueßen HL, de Leeuw BJ, de Boer AG, Verhoef JC, et al. (1998) Comparison of the effect of different chitosan salts and $\mathrm{N}$-trimethyl chitosan chloride on thepermeability of intestinal epithelial cells (Caco-2). J Control Release 51: 35- 46 .

45. Lamprecht A, Koenig P, Ubrich N, Maincent P, Neumann D (2006) Low molecular weight heparin nanoparticles: mucoadhesion and behaviour in Caco2 cells. Nanotechnology 17: 3673-3680.

46. Ward PD, Tippin TK and Thakker DR (2000) Enhancing paracellula permeability by modulating epithelial tight junctions. Pharm Sci Technol Today 3: 346-358.

47. Ramadas M, Paul W, Dileep K J, Anitha Y, Sharma C P (2000) Lipoinsulin encapsulated alginate-chitosan capsulesIntestinal delivery in diabetic rats. $J$ Microencapsul 17: 405-411.

48. Agnihotri SA, Mallikarjuna NN Aminabhavi TM (2004) Recent advances on chitosan-based micro-and nanoparticles in drug delivery. J Control Release 100: 5-28.

49. Hanazaki K, Nose Y, Brunicardi FC (2001) Artificial endocrine pancreas. J Am Coll Surg 193: 310-322.

50. Freitas RA (2005) Current status of Nanomedicine and Medical Nanorobotics. J Comput Theor Nanosci 2: 1-25.

51. Freitas RA Jr (2002) The future of nanofabrication and molecular scale devices in nanomedicine. Stud Health Technol Inform 80: 45-59.

52. http://thefutureofthings.com/news/1286/insulin-nanopump-for-accurate-drugdelivery.html.

53. Manish Mishra, Hemant Kumar, Kamlakar Tripathi (2008) Diabetic delayed wound healing and the role of silvernanoparticles. Digest Journal of Nanomaterials and Biostructures 3: 49-54.

54. Giugliano D, Ceriello A, Paolisso G (1996) Oxidative stress and diabetic vascular complications. Diabetes Care 19:257-267. 
Citation: Rahiman S, Tantry BA (2012) Nanomedicine Current Trends in Diabetes Management. J Nanomed Nanotechol 3:137. doi:10.4172/21577439.1000137

55. Feldman EL, Stevens MJ, Greene DA (1997) Pathogenesis of diabetic neuropathy. Clin Neurosci 4: 365-370.

56. Clark RA (1985) Cutaneous tissue repair, basic biologic considerations. I. J Am Acad Dermatol 13: 701-725.

57. Coleman DL (1982) Diabetes-obesity syndromes in mice. Diabetes 31: 1-6.

58. Yue DK, McLennan S, Marsh M, Mai YW, Spaliviero J, et al. (1987) Effects of experimental diabetes, uremia, and malnutrition on wound healing. Diabetes 36: 295-299.

59. Silhi N (1988) Diabetes and wound healing. J Wound Care 7: 47-51.

60. Warheit DB (2004) Nanoparticles: health impacts? Mater Today 7: 32-35.

61. Chung D (2003) Nanoparticles have health benefits too. New Scientist 179: 2410-2416.

62. Zhang F, Chan SW, Spanier JF, Apak F, Jin Q, et al. (2002) Cerium oxide nanoparticles: size-selective formation and structure analysis. Appl Phys Lett 80: 127-129.

63. Perebeinos V, Chan SW, Zhang F (2002) 'Madelung model' prediction for dependence of lattice parameter on nanocrystalsize. Solid State Commun123: 295-297.

64. Robinson RD, Spanier JE, Zhang F, Chan SW, Herman IP (2002) Visible thermal emission from sub-band-gap laser excited cerium dioxide particles. $J$ Appl Phys 92: 1936.

65. Kilbourn BT (1994) The encyclopedia of advanced materials, Pergamon Press Ltd, Oxford, USA.

66. Kofstad P (1972) Non stoichiometry electrical conductivity in binary metal oxides. Wiley, New York.

67. BT Kilbourn (1986) Encyclopedia of Materials Science and Engineering Pergamon press Ltd, Oxford, UK.

68. Becker S, Soukup JM, Gallagher JE (2002) Differential particulate air pollution induced oxidant stress in human granulocytes, monocytes and alveolar macrophages. Toxicol In Vitro 16: 209-218.

69. WD Kingery, HK Bowen, DR Uhlman (1976) Introduction to Ceramics. (2ndedn), John Wiley, New York.

70. Wright JB, Lam K, Hanson D, Burrell RE (1999) Efficacy of topical silver against fungal burn wound pathogens. Am J Inf Cont 27: 344-350 .

71. Grier N (1983) Silver and its compounds. Disinfection, Sterilization and Preservation. (3rdedn), Lea \& Febiger, Philadelphia.

72. Demling RH, DeSanti L (2006) Effects of silver on wound management Wounds 13: 4

73. Monafo WW, Moyer CA (1968) The treatment of extensive thermal burns with $0.5 \%$ silver nitrate solution. Ann NY Acad Sci 150: 937-945.
74. Fox CL Jr (1968) Silver sulfadiazine--a new topical therapy for Pseudomonas in burns. Therapy of Pseudomonas infection in burns. Arch Surg 96: 184-188.

75. Yin HQ, Langford R, Burrell RE (1999) Comparative evaluation of the antimicrobial activity of ACTICOAT antimicrobial barrier dressing. J Bum Care Rehab 20: 195-200.

76. Ruggiero D, Lecomte M, Michoud E, Lagarde M, Wiernsperger N (1997) Involvement of cell-cell interactions in the pathogenesis of diabetic retinopathy. Diabetes Metab 23: 30-42.

77. Guo R, Song Y, Wang G, Murray RW (2005) Does core size matter in the kinetics of ligand exchanges of monolayer-protected Au clusters? J Am Chem Soc 127: 2752-2757.

78. Yakimovich NO, Ezhevskii AA, Guseinov DV, Smirnova LA, Gracheva TA et al. (2008) Antioxidant properties of gold nanoparticles studied by ESR spectroscopy. Russian Chemical Bulletin 57: 520-523.

79. BarathManiKanth S, Kalishwaralal K, Sriram M, Pandian SR, Youn HS, et al. (2010) Anti-oxidant effect of gold nanoparticles restrains hyperglycemic conditions in diabetic mice. J Nanobiotechnology 8: 16.

80. Jain KK (2008) Nanomedicine: application of nanobiotechnology in medical practice. Med Princ Pract 17:89-101.

81. Surendiran A, Sandhiya S, Pradhan SC, Adithan C (2009) Novel applications of nanotechnology in medicine. Indian J Med Res 130: 689-701.

82. Nel A, Xia T, Madler L, Li N (2006) Toxic potential of materials at the nanolevel. Science 311: 622-627.

83. Cavaliere-Jaricot S, Darbandi M, Kuçur E, Nann T (2008) Silica coated quantum dots: a new tool for electrochemical and optical glucose detection. Microchim Acta 160: 375-383.

84. Michalet X, Pinaud FF, Bentolila LA, Tsay JM, Doose S, et al. (2005) Quantum dots for live cells, in vivo imaging and diagnostics. Science 307: 538-544.

85. Medina C, Santos-Martinez MJ, Radomski A, Corrigan OI, Radomski MW (2007) Nanoparticles : pharmacological and toxicological significance. $\mathrm{Br} J$ Pharmacol 150: 552-558.

86. Lam CW, James JT, McCluskey R, Hunter RL (2004) Pulmonary toxicity of single-wall carbon nanotubes in mice 7 and 90 days after intratracheal instillation. Toxicol Sci 77: 126-134.

87. Elder A, Gelein R, Silva V, Feikert T, Opanashuk L, et al. (2006) Translocation of inhaled ultrafine manganese oxide particles to the central nervous system. Environ Health Perspect 114: 1172-1178.

88. Oberdorster G, SharpZ, Atudorei V, Elder A, Gelein R, et al. (2004) Translocation of inhaled ultrafine particlesto the brain. Inhal Toxicol 16: 437-445.

89. Radomski A, Jurasz $\mathrm{P}$, onso-Escolano D, Drews M, Morandi M, et al. (2005) Nanoparticle-induced platelet aggregation and vascular thrombosis. $\mathrm{Br} \mathrm{J}$ Pharmacol 146: 882-893.

90. Chen Z, Meng H, Xing G, Chen C, Zhao Y, et al. (2006) Acute toxicological effects of copper nanoparticles in vivo. Toxicol Lett 163: 109-20.

Submit your next manuscript and get advantages of OMICS Group submissions

Unique features:

- User friendly/feasible website-translation of your paper to 50 world's leading languages

Audio Version of published paper

Digital articles to share and explore

Special features:

- 200 Open Access Journals

15,000 editorial team

21 days rapid review proces

Quality and quick editorial, review and publication processing

Indexing at PubMed (partial), Scopus, DOAJ, EBSCO, Index Copernicus and Google Scholar etc

Sharing Option: Social Networking Enabled

Authors, Reviewers and Editors rewarded with online Scientific Credits

Better discount for your subsequent articles

Submit your manuscript at: www.editorialmanager.com/biochem 